\title{
Journey Through the Groan Zone with Academics and Practitioners: Bridging Conflict and Difference to Strengthen Disaster Risk Reduction and Recovery Work
}

\author{
Katherine E. Browne ${ }^{1} \cdot$ Caela O'Connell $^{2} \cdot$ Laura Meitzner Yoder $^{3}$
}

Published online: 12 September 2018

(C) The Author(s) 2018

\begin{abstract}
Academic-practitioner divides in disaster management and research can be persistent and pernicious, bearing consequences for disaster survivors and future affected populations. The gap between disaster professionals and academic researchers is often treated as an unavoidable structural problem or a neutral accident of professional silos and circumstance. We suggest that these gaps are not neutral, and that they can and must be overcome. With hundreds of millions of people affected by disaster each year and recovery costs skyrocketing, there is urgency in connecting researcher and practitioner knowledges to avoid expensive mistakes and most importantly, to decrease human suffering. Yet the difficulties that US academic anthropologists and practitioners experienced in their efforts to collaborate became evident in a cross-sector National Science Foundation (NSF)-funded workshop on the relevance of culture in disaster work. We suggest and illustrate how more systematic cross-field communication can be operationalized through engaging in an ongoing and relational process of bridging. Such a process can offer long-term benefits to the people and institutions involved, dramatically enhance the science of disaster management, and help reduce the social and material costs of disaster impacts.
\end{abstract}

Katherine E. Browne

kate.browne@colostate.edu

1 Department of Anthropology, Colorado State University, Fort Collins, CO 80523, USA

2 Department of Anthropology - Disasters, Displacement, and Human Rights Program, University of Tennessee, Knoxville, TN 37996, USA

3 Program in Human Needs and Global Resources, Wheaton College, Wheaton, IL 60187, USA
Keywords Academic and practitioner divide $\cdot$ Applied research · Cross-sector communication - Culture and disaster $\cdot$ Disaster anthropology $\cdot$ Disaster management

\section{Introduction}

We have all been there. A conference presentation where the question arises, "Why didn't you include practitioners in this work?" Or learning midway through a project about a body of research that would have saved design time or averted early missteps. Frustrated colleagues muse that their learning and insights will never make a difference because it is years to publication and then the article sits in a closed academic journal or project report—read by few, informing few. The impetus to bridge what is often referred to as the practitioner-academic divide has drawn scholarly attention for decades (Eriksson and Sundelius 2005; Trainor et al. 2018). Our article focuses on the US context, where the separation of these groups is apparent and where our own experience can help illuminate the grip of these divides.

We propose that there are common misconceptions about the nature of this divide that have made it very difficult to bridge. The divide is not mysterious or accidental; it is the product of different cultures of work, practice, goals, language, and some professional animus. Moreover, the scale and temporality for practitioner and academic work are actively misaligned. These misalignments were made particularly obvious to the authors who participated recently in a small workshop with a mix of practitioners and academics focused on the roles of culture in disaster research, risk mitigation, and recovery. Though not the focus of the workshop, the academic-practitioner divide 
became prominent as we worked. Following that workshop, we sought out literature that could speak to our struggle to work with and through these divides. In this article, we reflect on what many of those in attendance experienced as a break-through-the-divide. Our primary takeaway is that there is sustaining value in the process of bridging rather than focusing entirely on desired outcomes from such bridges. In the following sections, we present common themes within the literature about these divides and their solutions, existing disaster-related efforts to improve outcomes from bridges, a brief ethnographic account of the complexity of these divides in action through our workshop, and several suggestions for those working in disaster fields who are interested in the process of bridging to overcome divides.

\section{The Worlds of Academics and Practitioners}

Recently, a team of scholars have attempted to reframe the academic-practitioner divide in order to focus on unifying goals and avoid reifying an "us/them" perception (Trainor et al. 2018). It is certainly true that there is no "single" or "homogeneous" group of disaster researchers or of disaster practitioners. In fact, there are of course many kinds of differences among members within each group and some people who work across these groups may identify with both or neither. Thus, we heartily support unifying efforts to avoid default assumptions of polarized groups. In fact, our direct experience validates the recognition of heterogeneity among practitioners and academics. Yet, as we describe in this article, tensions became strongly evident during our workshop, which makes it clear that such divides are active. And because we believe these divides contribute to unnecessary suffering, the stakes of such a position become significant. Our approach is thus to recognize that in the broadest sense, divides between practitioners and academics emerge from whole environments that are organized to meet different purposes. In order to position ourselves to actively address these unaligned purposes, we must understand the distinct worlds of each.

\subsection{Communication Barriers}

Academics and practitioners seem to inhabit distinct universes. The most recognized source of disconnection stems from issues of communication, especially inaccessible language widespread in jargon-laden academic writing or professional project reports that carry much presumed knowledge of institutional norms, industry acronyms, and other specific terminology. Language critiques are closely followed by issues with the length of academic articles, and the publication in outlets unknown and inaccessible to practitioners for reasons of cost and visibility (Bushouse et al. 2011; Bartunek and Rynes 2014; Cook and Elwell 2014; Hutt and Walker 2015). Some have recognized that these communication problems are more tenacious than language adjustment and publication style alone can address. They are indeed rooted in problems related to framing and to assumptions that drive arguments. In many respects, academic and practitioner "logics" are simply incompatible: researchers are driven by academic curiosity and are trained to identify their more abstract "research problem" in relation to existing literature; practitioners identify their problems as the pressing concerns facing them in a given context, made evident to them as sector experts and within their institutional mandates to respond (Bushouse et al. 2011; Bartunek and Rynes 2014).

Many argue that to solve these problems, academics need to write for more public venues and translate longer work into short, clear summaries that are relevant to practitioner needs. Likewise, academics need to get better at integrating practitioner-generated work. Researchers often overlook or are unaware of important work being generated and disseminated by practitioners via research reports, white papers, and other nonpeer-reviewed reports. They need to also demonstrate the relevance of their findings to real-world problems that concern a broader public (Wai and Miller 2015). Some suggest that there is such emphasis in the academy on "rigor" that the concern for "relevance" (what most concerns practitioners) is neglected (Bartunek and Rynes 2014). There are important shifts occurring on this front, as scholars are increasingly writing in more accessible manners. This is especially visible in writing by "engaged" or "public-facing" anthropologists who are working to address practitioner critiques through writing for open-access media outlets such as SAPIENS, ${ }^{1}$ The Mark News, ${ }^{2}$ and Anthro\{dendum . $^{3}$ Many traditional scholarly journals have begun offering blogposts, roundtable online discussions of current topics, and/or open-access spaces.

A small but growing number of people straddle academic and practitioner worlds, individuals that Posner (2009) calls "pracademics." Pracademics, he points out, are well positioned to take on roles bridging communication between research and practice. But to date, research that explores how academics and practitioners experience

\footnotetext{
${ }^{1} \mathrm{http} / / / \mathrm{www}$. sapiens.org for example Sienna Craig's piece on the 2015 earthquake in Nepal https://www.sapiens.org/culture/nepalearthquakes/.

2 http://www.themarknews.com see for example the CADAN piece on the role of culture in disaster aid planning http://www.the marknews.com/2017/07/10/a-helping-hand/.

3 https://anthrodendum.org for example Zoe Todd's piece on toxicity and Harvey in Texas https://anthrodendum.org/2017/12/08/the-rela tivity-of-toxicity/.
} 
these divides is most often generated by academics and discussed in their academic journals, perpetuating the divide. The perspectives of practitioners or pracademics about these divides are nearly always missing from these accounts and thus commonly ignored (Bartunek and Rynes 2014).

\subsection{Generating Public Scholarship}

Despite the variety of obstacles, the benefits of closer collaborations among researchers and practitioners are widely evident (Cook and Elwell 2014; Hutt and Walker 2015). For example, collaboration regarding the methods used to generate research, as well as whether and how research is used, could help practitioners and researchers come to a better understanding of each other's priorities. Approaches to generating more practitioner-sensitive research could involve the simple practice of academics asking practitioners what research questions could help them solve problems. What insights and research findings would practitioners like to have, but are unable to produce themselves for lack of time, methods, or resources. Scholars also note that systemic factors that contribute to separate universes must be recognized and negotiated to support such shifts. To this end, institutions of higher learning could examine academic reward systems to increase the incentives for developing research questions aimed at solving real-world problems (Garland 2016; Scaratti et al. 2017). Others suggest that reforming the tenure and promotion criteria could promote new kinds of quality and a higher applicability of research. This strategy would require effectively evaluating engaged scholarship, especially by making peer review more inclusive (O'Meara et al. 2015).

Some authors suggest that practitioners are increasing their rigor by integrating researcher insights and methods of evaluation (Cook and Elwell 2014). A number of authors stress that this type of solution begins by recognizing the difference between "Mode 1" and "Mode 2" research goals. Mode 1 research follows the model of traditional scholarship and its end product is acutely academic and is not readily accessible for application, thus limiting the work's immediate value to practitioners. In contrast, Mode 2 research engages teams of multiple stakeholders and combines both the rigor of academic work and the relevance of practitioner needs (Bushouse et al. 2011; Gray et al. 2011; Bartunek and Rynes 2014; Cook and Elwell 2014).

Practitioners may regard researchers in stereotypical ways (Gunasekaran et al. 2017), as privileged people who work in institutions that have no connection to the communities where they are located. That sheltered environment may seem to offer faculty enviable freedom of time, opportunities to pursue funding, and rewards for published work riddled with incomprehensible jargon-a world away from the schedules and pressures practitioners face. But there are critically important counter trends on the rise among scholars and changing priorities across the arenas of scholarship, writing, and assessment within the academic world.

One example of shifting priorities has been a wider embrace of the ethic to build strong connections between academic knowledge producers and nonacademic publics. This approach found its modern voice and institutional urgency in Ernest Boyer's (1990) work, which argues that social and environmental issues impart a greater timeliness to bridging than ever before. Boyer frames this shift not as an invention, but a reconciling with the past, pressing for the academy to "reaffirm its historic commitment to [...] the scholarship of engagement" (Boyer 1996, p. 11). Others suggest that solving the divide needs reinforcement beyond academics and practitioners morphing into one another's professional spaces, advocates instead for professional "intermediaries" to be formed of individuals who specialize in the work of bridging knowledge and process gaps between practitioners and academics (Gunasekaran et al. 2017).

\subsection{Identifying and Embracing Common Goals}

Finally, some fields have made truly notable strides in bridging the worlds of practitioners and academics by identifying common goals and overcoming divides in ways that have contributed to improved services and well-being for their beneficiaries. A model of potential collaboration and transcendence of the divide is one we see often in medical and health settings especially situated in the fields of public health, medical anthropology, social medicine, and social work. In these spaces, with the health outcomes of human beings as the unifying goal, researchers and practitioners have done a lot of intentional work, and continue to recognize that much remains to be done (Ammerman et al. 2014). One way this has happened is through the use of "culture brokers," people who straddle cultural worlds of doctors and patients. For example, the widely acclaimed medical anthropology book The Spirit Catches You and You Fall Down chronicles the compounding difficulties and outcomes of cultural gaps between California medical practitioners and a Hmong patient's family and community (Fadiman 2012). In the 2012 revised edition, the author noted her surprise in the widespread, sustained public interest in this story. But the Afterword also describes a range of ways in which both hospital practice and medical education have been subsequently transformed by incorporating a greater cultural awareness. We hope for a similar contribution of 
anthropology to disaster response, and look forward to how disaster recovery practice prompts new questions and approaches in anthropology.

\section{Actors and Urgency in the Field of Disaster Recovery: Disaster Social Scientists, Disaster Practitioners, and Disaster "Pracademics"}

In post-disaster management, the gap between those who practice and those who research creates problems that need urgent remediation. Disconnected researcher and practitioner knowledges can produce costly mistakes that perpetuate human suffering (Browne 2013, 2015; Trainor and Subbio 2014). It is not a great leap to imagine that unifying goals from the health and medical settings could also be identified for the fields of disaster risk reduction and recovery. There the imperative to help in the midst of hurt is an ever-present force.

Some researchers have called for the use of culture brokers to connect research insights to practitioner needs (Browne 2015; Marlowe and Bogen 2015) specifically in disaster settings. Other bridging efforts specific to disaster fields include recruiting practitioners to teach college classes on the side. Another example includes Federal Emergency Management Agency's Emergency Management Higher Education Program that aims to promote and guide the development of college-based emergency management education for future emergency managers and other interested personnel. In North America there are over 130 designated Hazards Centers that promote dialogue and exchange among disaster researchers, practitioners, and policymakers. The University of Colorado Natural Hazards Center hosts an annual Hazards Workshop for 500 disaster scholars and professionals in government, business, and non-profit sectors. ${ }^{4}$ In the field of anthropology, the annual meeting of the Society for Applied Anthropology formed a Disaster and Applied Anthropology "topical interest group" in 2010. Each year, more than 100 disaster anthropologists and professionals interact at these meetings. Despite such efforts, there is still insufficient substantive or sustainable cross-fertilization between disaster academics and practitioners.

In part, the divides are difficult to transcend without clarity about how to enter into conversations with one another or how to sustain an engaged relationship from a one-off conversation. This lack of clarity and the chasm between worlds gets compounded by the time required to

\footnotetext{
${ }^{4}$ See https://hazards.colorado.edu/news/center-news/putting-researchon-the-map-new-nhc-tool-lets-you-chart-disaster-research-centers for recent additions to the Natural Hazards Center's longstanding efforts to connect research and practice on hazards across the North America/ Caribbean region.
}

translate one's own research, or to seek out inaccessible academic work. Neither group has widely institutionalized incentives to bridge the divide. If the gaps could be solved by urging academics to write in more accessible ways and use more familiar outlets of publication, we would already see far more "uptake" of scholarship among practitioners. Suggesting such a template, however, assumes a great deal of substantive conversation has already taken place and that all parties are already clear on their shared commitments and common goals. We find that this work has not been done widely, and consequently in failing to substantively bridge, many efforts have remained relegated to academic communities.

\section{Encountering the Groan Zone in a Workshop for Anthropologists and Practitioners on the Relevance of Culture in Disasters}

Trainor and Subbio (2014) propose that the single best way to improve disaster science and management is to create spaces for meaningful conversation among practitioners and academics. They also suggest that developing interpersonal relationships across these divides can make it easier to learn from each other. Recognizing the challenges of creating those first steps that begin genuine conversation, Browne and O'Connell convened a facilitated workshop, with funding from the US National Science Foundation. The purpose of the workshop was to offer a structure for disaster researchers and professionals to begin a conversation about the relevance of culture in disaster recovery. This section offers a few ethnographic details from the workshop that we identify as critical moments in the process of bridging. We offer these examples not to suggest that divide-bridging activities require professional facilitators or retreat spaces, but to illustrate how underlying tensions, individuals' prior experiences, and ultimately, the human connections forged in that space were foundational elements of the process to accomplish the bridging that later took place.

\subsection{Journey to and Through the "Groan Zone"}

In mid-October 2016, 12 scholars and practitioners and two facilitators gathered for a three-day intensive workshop on the "Relevance of Culture in Disaster Recovery." Nestled away in the foothills of Colorado and surrounded by the colors of autumn, we had secured a setting that we hoped could keep tough dialogue in perspective. In the midst of our second day while listening to an academic explain how "disaster cycles are effectively false constructs" and that "disaster begins long before a catastrophic event," a highly experienced practitioner suddenly exclaimed, “I don't even 
follow what you are saying. Just give me something I can use!" The conflict between some academics and some practitioners had been simmering below the surface from the beginning of the workshop, but this candid confession and assertion of what was needed played a pivotal role in driving the group into the classic "groan zone" (Kaner 2014). The "groan zone" is what facilitators sometimes call a place in which workshop participants simply feel at odds; the hope for transcending differences, or accomplishing the intended goals of the group seems increasingly remote (Fig. 1).

We wrestled with the groan zone for the rest of our time together. How workshop participants managed the groan zone, the value of the process of wrestling with this uncomfortable space, and the ways in which we were able to move out of it and on to future collaboration prompted us to write this article. We believe that the types of conversations and connections our group experienced through this workshop offer a way to approach the bridging of practitioner and academic divides for disaster professionals and researchers.

The groan zone in our workshop was raw. Though less often identified (Bartunek and Rynes 2014), it is important to note that our divides were not only between researchers and academics, but also internal to each group. The workshop created a space where implicit and then explicit tensions and conflict appeared and a shared moment in which these tensions were brought into the open. Although these experiences were not the intent or focus of the workshop, it became clear that this work, this uncomfortable process, was central if we hoped to address our stated goals. The workshop began with intensive activities where participants who mostly did not know each other willingly exchanged information about themselves, a compact version of how they grew up and what had brought them to this place and this point in their careers. The focus on sharing one's own story and listening to the experiences of others drew people into a sense of shared purpose. Early on it is probably safe to say that everyone felt a degree of connection to the process, and everyone felt a sense of new connections to at least some of the people in the room.

These early personal connections were instrumental in how our group navigated the groan zone. Many of the communication and language issues cited above arose in our conversations, along with frank discussions of our institutional cultures, systemic and personal limitations of time, job expectations, and the realities of the funders and financing availability. Two examples during our tense conversations illustrate why we argue that for disaster-focused work, the academic-practitioner divide is not neutral, but actively harmful. First, following a long conversation with indications that workshop participants were becoming polarized, the facilitators asked all participants identified as practitioners to pull their chairs into an inner circle. Those who identified with both worlds placed their chairs in-between the inner and outer circles. The academics remained
Fig. 1 The "groan zone" depicts the time in a group process when "divergent" thinking (the left side of the diamond where all ideas are heard), shifts into "convergent" thinking (the right side of the diamond where priorities must be identified to winnow the field). The need to drastically reduce the ideas to a realistic few creates the groan zone tension, itself vital for sustainable work and crosssector understanding (Kaner 2014)

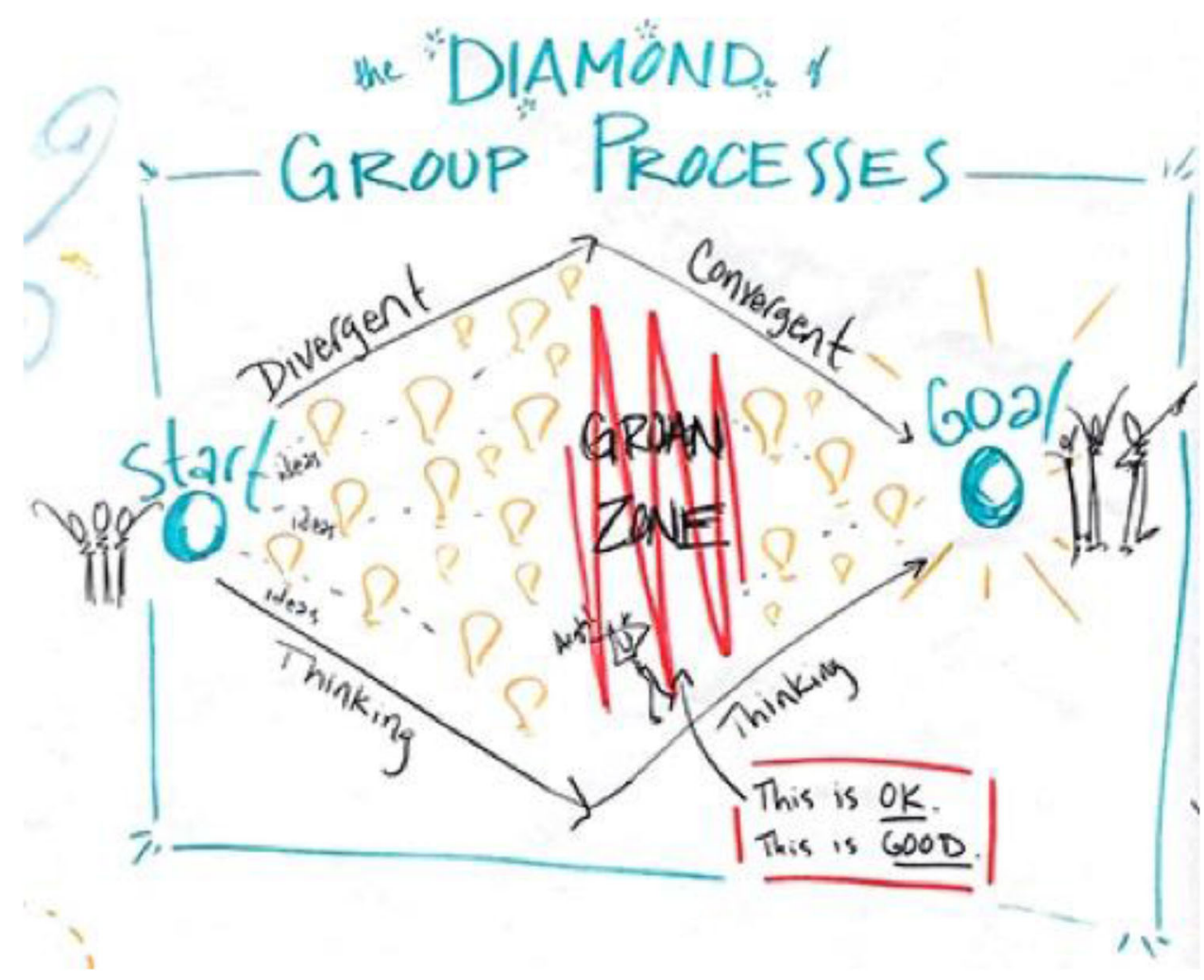


in the outer circle and were instructed to remain quiet while those in the inner circle spoke about their experiences. At a few points, outer circle academics burst into the space created for practitioners' voices with attempts to negate or explain why certain points were problematic. In these moments the academic imperiousness and pretension expressed in talking over the practitioners was on full display, but facilitation held us all to the terms of this space. For the first time in two intense days of exchange, practitioners held the floor and made their case for a nuanced and informed approach to disaster recovery that worked toward actionable outcomes.

\subsection{Moving Beyond the Groan Zone}

The second moment came shortly thereafter, when in frustration, several academics described earnest, unsuccessful efforts to get their research heard by the governments and nongovernmental organizations (NGOs) working in disaster recovery at their field sites. These were emotionally charged moments as researchers described being turned away and ignored, and yet later asked, "Why didn't you say it sooner?" Academics shared how they had witnessed such impasses and seen them contribute tangible harm within the communities where they worked. Academics had seen how communication failures or cultural gaps between local people and outside helping agencies had eroded the possibility for improved outcomes in the recovery process. Academics who had attempted collaborations with practitioner work expressed their mistrust, disappointment, and anger. Their stories allowed practitioners to see a more personal side of academics and their work that is not always apparent in the studied and theoryladen language of scholarly writing or presentations. A highly experienced practitioner, Robert McCleod, later reflected on this in a written statement for his participation in a presentation we gave at the Society for Applied Anthropology in 2016, writing:

Until I was invited to the workshop, I had no idea that the academic community was engaged in post-disaster cultural sensitivities. Why, I thought, haven't our paths crossed earlier? I've participated in disaster recovery efforts [for decades...] and I do not recall meeting an academic or academic/practitioner working in a recovery context. The workshop changed this dynamic with unanticipated consequences. It was a struggle for the group to find common ground. It became clear to me that practitioners and academics speak very different languages when it comes to disaster recovery work. I do not have a theoretical position on disaster recovery. I have a practical one based on extensive post-disaster field work. As a non- academic practitioner, I became extremely frustrated and felt isolated.

As a collective, the physical, intellectual, and emotional process of the workshop took us through moments that broke through well-rehearsed framings, and opened up our conversations. Despite being stressful and unpleasant, these tensions are known to support productive conversations, by revealing assumptions, gaps, and unaddressed issues (Bartunek and Rynes 2014). Ultimately, our workshop was flexible enough that when things became tense, we were able to recalibrate and invest necessary time and energy in the process of bridging (Carcasson 2016). Building these kinds of collaborations is challenging work, and too often, the attention and energy are directed only to the potential outcomes. By the time we adjourned the workshop, there was an overwhelming sense that we had generated hardwon goodwill among us, and most of us realized that the path forward was through our shared goals to improve disaster recovery as a process and to reduce suffering and hardship for survivors. Despite undeniable differences, three days of intense work left us with a pathway for more real and honest conversation that would carry us into future projects together (Fig. 2).

\section{Conclusion: The Other Side of the Groan Zone}

Moving through the groan zone is defined as successfully coming to a point of convergence and then closure, if not consensus (Kaner 2014). This is the final lesson of the workshop: bridging is an ongoing process requiring investment. Like a good marriage, there is no single ritual after which we have achieved a bond we can then take for granted. Following the workshop, most participants reached a decision to continue work on bridging together. We formed a network, called the Culture and Disaster Action Network (CADAN), with members pursuing the types of research and action that facilitate future bridging. ${ }^{5}$ We know we will enter the groan zone regularly, that the process is ongoing, and that we are all committed to the time, friction, and possibilities the groan zone will entail.

The value of recognizing the divide, understanding its constituent parts, and bridging the knowledges of all parties cannot be overstated. What makes the stakes of this bridging process so high? With the rapid increases in both the frequency and scale of disasters, and with hundreds of millions of people affected each year by these disasters, there is every reason to prioritize getting critical research and the realities of practice integrated. We encourage

\footnotetext{
5 For more information about CADAN please visit http://www. cultureanddisaster.org to read about current activities, past projects, membership, and open access resources.
} 
Fig. 2 Emerging from the groan zone returned us to the foundations of what had brought us together-to build relationships between practitioners and academics. This graphic provided a visual road map of our discussion about the value and purpose of the uphill effort to create these relationships, and kept the many strategies we identified for doing so in plain sight. This was one of nine large mural-sized drawings that graphic facilitator Karina Mullen Branson created during our workshop

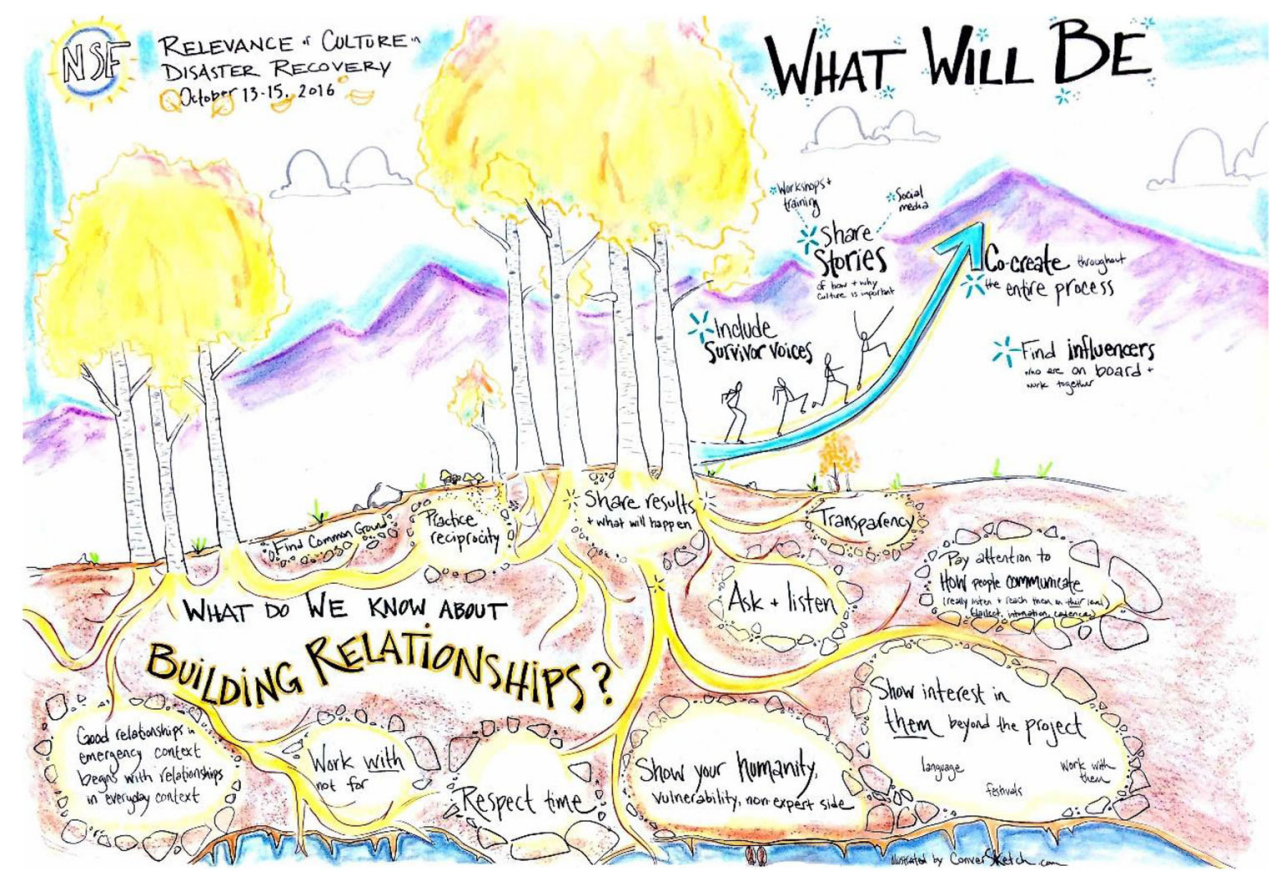

reflective practitioners and engaged academics to invest in the process of bridging and help us create a much-needed paradigm shift in how the work of disaster risk reduction and recovery is achieved. With insight and clarity from bridging the work of experts, there is immense suffering that could be reduced or eliminated.

Acknowledgements The authors thank Adam Koons, Laura Olson, Robert MacLeod, Martha King, and IIan Kelman for their valuable review, assistance, and comments on this piece. Many thanks to our fellow CADAN members for your continued input, good humor, and ongoing journey through the Groan Zone with us. Funding for Browne and O'Connell's Culture and Disaster Workshop came from the US National Science Foundation's Program in Cultural Anthropology (award \# BCS-1647248) and we are forever grateful for this support.

Open Access This article is distributed under the terms of the Creative Commons Attribution 4.0 International License (http://crea tivecommons.org/licenses/by/4.0/), which permits unrestricted use, distribution, and reproduction in any medium, provided you give appropriate credit to the original author(s) and the source, provide a link to the Creative Commons license, and indicate if changes were made.

\section{References}

Ammerman, A., T.W. Smith, and L. Calancie. 2014. Practice-based evidence in public health: Improving reach, relevance, and results. Annual Review of Public Health 35: 47-63.

Bartunek, J.M., and S.L. Rynes. 2014. Academics and practitioners are alike and unlike. Journal of Management 40(5): 1181-1201.

Boyer, E.L. 1990. Scholarship reconsidered: Priorities of the professoriate. New York: The Carnegie Foundation for the Advancement of Teaching.
Boyer, E. 1996. The scholarship of engagement. Journal of Public Service and Outreach 1(1): 11-20.

Browne, K.E. 2013. Standing in the need: Communication failures that increased suffering after Katrina. Anthropology Now, 30 March 2013. http://anthronow.com/print/standing-in-the-needcommunication-failures-that-increased-suffering-after-katrina. Accessed 20 Jun 2018.

Browne, K.E. 2015. Standing in the need: Culture, comfort, and coming home after Katrina. Austin: University of Texas Press.

Bushouse, B.K., W.S. Jacobson, K.T. Lambright, J.J. Llorens, R.S. Morse, and O.-O. Poocharoen. 2011. Crossing the divide: Building bridges between public administration practitioners and scholars. Journal of Public Administration Research and Theory 21(S1): i99-i112.

Carcasson, M. 2016. Tackling wicked problems through deliberative engagement. National Civic Review 105(1): 44-47.

Cook, J., and N. Elwell. 2014. Bridging the academic-practitioner divide. Routledge Third World Quarterly 35(3): 507-550.

Eriksson, J., and B. Sundelius. 2005. Molding minds that form policy: How to make research useful. International Studies Perspectives 6(1): 51-71.

Fadiman, A. 2012. The spirit catches you and you fall down: A Hmong child, her American doctors, and the collision of two cultures. New York: Farrar, Straus, and Giroux.

Garland, J. 2016. One step forward, two steps backward? Difficulties and dilemmas with connecting hate crime policy and research. Criminal Justice Policy Review 27(6): 627-639.

Gray, D.E., P. Iles, and S. Watson. 2011. Spanning the HRD academic-practitioner divide: Bridging the gap through Mode 2 research. Journal of European Industrial Training 35(3): 247-263.

Gunasekaran, S., P. Krishnadevarajan, and F.B. Lawrence. 2017. Bridging the research-practice divide through the intermediary model. Advances in Developing Human Resources 19(3): 314-330.

Hutt, M.D., and B.A. Walker. 2015. Bridging the theory-practice gap in business marketing: Lessons from the field-The JBBM at 21. Routledge Journal of Business-to-Business Marketing 22(1-2): $67-72$. 
Kaner, S. 2014. Facilitator's guide to participatory decision-making. San Francisco: Wiley.

Marlowe, J., and R. Bogen. 2015. Young people from refugee backgrounds as a resource for disaster risk reduction. International Journal of Disaster Risk Reduction 14(Part 2): 125-131.

O’Meara, K., T. Eatman, and S. Petersen. 2015. Advancing engaged scholarship in promotion and tenure: A roadmap and call for reform. Liberal Education 101(3): 52-57.

Posner, P. 2009. The pracademic: An agenda for re-engaging practitioners and academics. Public Budgeting and Finance 29(1): 12-26.

Scaratti, G., L. Galuppo, M. Gorli, C. Gozzoli, and S. Ripamonti. 2017. The social relevance and social impact of knowledge and knowing. Management Learning 48(1): 7-64.
Trainor, J.E., and T. Subbio. 2014. Critical issues in disaster science and management: A dialogue between researchers and practitioners. FEMA Higher Education Project. https://udspace.udel. edu/bitstream/handle/19716/13418/Critical\%20Issues\%20in\% 20Disaster\%20Science\%20and\%20Management\%20-\%20Trai nor.pdf?sequence=1\&isAllowed=y. Accessed 1 Jul 2018.

Trainor, J.E., E.K. Stern, and T. Subbio. 2018. On bridging research and practice in disaster science and management: Unified system or impossible mission? In Handbook of disaster research, ed. H. Rodríguez, W. Donner, and J.E. Trainor, 161-178. Berlin: Springer.

Wai, J., and D. Miller. 2015. Here's why academics should write for the public. The Conversation. US edition. http://theconversation. com/heres-why-academics-should-write-for-the-public-50874. Accessed 27 Jun 2018 